\title{
Chloride Ion Penetration Resistance and Pore Structure of Magnesium Silicate Hydrate (M-S-H) Mortars
}

\author{
Tingting ZHANG ${ }^{\mathrm{a}}$, Ziming $\mathrm{HE}^{\mathrm{a}}$, Junnan $\mathrm{HAN}^{\mathrm{a}}$ \\ ${ }^{a}$ Faculty of Infrastructure Engineering \\ Dalian University of Technology \\ Dalian, China
}

\author{
Zhenlin $\mathrm{WU}^{\mathrm{b} *}$ \\ ${ }^{\mathrm{b}}$ School of Optoelectronic Engineering and \\ Instrumentation Science \\ Dalian University of Technology \\ Dalian, China \\ e-mail: zhenlinwu@dlut.edu.cn
}

\begin{abstract}
The main purpose of this paper is to study the chloride ion penetration resistance and pore structure of magnesium silicate hydrate cement (MSH) mortars. The chloride ion penetration resistance of MSH mortars with different water-to-cement ratios $(0.5,0.55,0.6)$ and different sand rates $(25 \%, 50 \%, 75 \%)$ was studied and compared to ordinary Portland cement (OPC) mortars. The pore structure of magnesium silicate hydrate mortar was tested using mercury intrusion porosimetry (MIP). The results indicate that the chloride ion diffusion coefficient becomes larger with an increase in the water-to-cement ratio and sand rate; the coefficient of MSH mortars is much smaller than that of OPC mortars. The results of MIP show that MSH mortars generally have gel pores measuring less than $10 \mathrm{~nm}$; however, the pore size of OPC mortars is dominated by pores measuring $10 \mathrm{~nm}$ to $100 \mathrm{~nm}$. Finally, MSH mortars were found to be less porous than OPC mortars.
\end{abstract}

Keywords- magnesium silicate hydrate mortar; chloride ion penetration resistance; pore structure

\section{INTRODUCTION}

Magnesium silicate hydrate cement (MSH) is a new type of cementitious material. Literature has indicated that the hydration products of $\mathrm{MgO}-\mathrm{SiO}_{2}-\mathrm{H}_{2} \mathrm{O}$ system are primarily composed of $\mathrm{Mg}(\mathrm{OH})_{2}$ and $\mathrm{MSH}$ gel, which is formed by the reaction of $\mathrm{MgO}$ and amorphous silica in the presence of sodium hexametaphosphate (Na-HMP) [1-3]. The properties of magnesium silicate hydrate cement have also been studied by some scholars[4,5].

The $\mathrm{pH}$ of MSH cement is lower than that of ordinary Portland cement (OPC) and is therefore better suited to encapsulating nuclear waste and some heavy metal ions[6]. It is also used in wall insulation materials, refractory castables, and other fields due to its light weight, excellent mechanical properties, and high raw material temperature[7].
Although MSH cement has been theoretically improved, its durability has not been empirically tested; therefore, its durability is worth studying. There are many forms of deterioration that threaten the durability of cement-based materials, most of which is related to the intrusion of water and chlorine salts[8]. There are many methods to prevent corrosion in concrete, but the most basic and effective way is by improving the properties of cement-based materials [9].

Extensive research has been done on OPC with regard to chloride ion penetration[10-11], but in the case of MSH cement, its performance under chloride ion penetration remains unknown. As a new type of building material that also has sound development prospects, MSH's performance under chloride ion penetration warrants further study. Therefore, the main aim of this paper is to study the effect of the water-to-cement ratio and sand content on the chloride ion diffusion coefficient of MSH mortars. The study also intends to compare MSH and OPC mortars under the same impermeability conditions. The pore size distribution of cement mortars is measured using mercury intrusion porosimetry (MIP).

\section{EXPERIMENTAL}

\section{A Materials}

This study used commercially available $\mathrm{MgO}$ ( $\mathrm{MgO}$; MagChem 30, M.A.F. Magnesite B.V., The Netherlands), silicate fume (SF; Elkem Materials Ltd., Shanghai, Chnia), OPC (P.O 42.5R, Onoda Cement Co., Ltd., Dalian, China), and sodium hexametaphosphate (Na-HMP, chemical grade, >95\% purity; Sinopharm Chemical Reagent Co., Ltd., Shanghai, China). According to previous research[12], fine silica sand was used in the preparation of all samples. The chemical compositions of the raw materials are reported in Tab. 1.

TABLE I. CHEMICAL COMPOSITION OF RAW MATERIALS

\begin{tabular}{cccccccccc}
\hline $\begin{array}{c}\text { Chemical Composition } \\
\text { (wt.\%) }\end{array}$ & $\mathbf{S i O}_{\mathbf{2}}$ & $\mathrm{Al}_{\mathbf{2}} \mathbf{O}_{\mathbf{3}}$ & $\mathbf{F e}_{\mathbf{2}} \mathbf{O}_{\mathbf{3}}$ & $\mathbf{C a O}$ & $\mathbf{P}_{\mathbf{2}} \mathbf{O}_{\mathbf{5}}$ & $\mathbf{M g O}$ & $\mathbf{K}_{\mathbf{2}} \mathbf{O}$ & $\mathbf{N a}_{2} \mathbf{O}$ & $\mathbf{S O}_{\mathbf{3}}$ \\
\hline Silica fume & 94.71 & 0.23 & 0.24 & 0.68 & 0.37 & 1.19 & 1.74 & 0.35 & 0.36 \\
MgO & 0.35 & 0.07 & 0.15 & 0.87 & - & 98.3 & - & - & 0.05 \\
OPC & 21.45 & 5.24 & 2.89 & 61.13 & - & 2.08 & - & 0.77 & 2.50 \\
\hline
\end{tabular}


TABLE II. MIXTURE PROPORTIONS OF MORTAR

\begin{tabular}{ccccc}
\hline $\begin{array}{c}\text { Cement } \\
\text { Type }\end{array}$ & $\begin{array}{c}\text { Samlpe } \\
\text { No. }\end{array}$ & $\begin{array}{c}\text { Cement } \\
\text { (wt.\%) }\end{array}$ & $\begin{array}{c}\text { Water-to-Cement } \\
\text { Ratio }\end{array}$ & $\begin{array}{c}\text { Sand Content } \\
\text { (wt.\%) }\end{array}$ \\
\hline & N1 & 75 & 0.5 & 25 \\
N-S-H & N2 & 50 & 0.5 & 50 \\
& N3 & 25 & 0.5 & 75 \\
& N4 & 50 & 0.55 & 50 \\
\hline O-P-C & N5 & 50 & 0.6 & 50 \\
\hline
\end{tabular}

a. The composition of MSH paste is MgO: SF: $\mathrm{Na}-\mathrm{HMP}=40: 60: 2$.

\section{B Methods}

According to the formulation in Tab. 2, specimens were cast in steel molds to create $40 \mathrm{~mm} \times 40 \mathrm{~mm} \times 160 \mathrm{~mm}$ and $\phi 100 \mathrm{~mm} \times 100 \mathrm{~mm}$ samples. The molds were covered with plastic wrap and moved to the standard curing room with a relative humidity of $>95 \% \mathrm{RH}$ to prevent samples from drying out while curing. Specimens were demolished within $(24 \pm 2)$ hours and then placed in standard curing chambers to undergo strength and chloride ion penetration resistance tests, respectively. According to Chinese Standard GB/T50082-2009, the chloride ion diffusion coefficient was evaluated using an apparatus to determine the rapid chloride migration coefficient (RCM-NTB Beijing NELD Instrument Co., Ltd., China). Seven days before the test, specimens were taken to coring at $\phi 100 \mathrm{~mm} \times 50 \mathrm{~mm}$ and cured until the test ages. After the mechanical properties of the specimen were tested, select the shape of the rules of crushed samples of about $2 \mathrm{~g}$ placed in the sealed bag and terminate hydration with alcohol. The prepared crushed samples were placed in a vacuum oven at $50^{\circ} \mathrm{C}$ for 48 hours prior to the MIP and SEM tests.

\section{RESUlTS AND DISCUSSION}

\section{A. Mechanical Properties}

Fig. 1(a) presents the results of the MSH mortars' flexural and compressive strength after curing for 28 days curing withunder different water-to-cement ratios. From Fig. 1(a), we can see that flexural and compressive strength decreased gradually over 28 days while the water-to-cement ratio increased. When the water-to-cement ratio reached 0.5 and the sand content reach $50 \%$, the compressive strength of MSH mortar was $58.6 \mathrm{Mpa}$; hence, MSH cement showed good mechanical properties. Fig. 1(b) displays the results the MSH mortars' flexural and compressive strength of the MSH mortars after curing for 28 days with different sand contents. As shown in Fig. 1(b), the flexural and compressive strength of the MSH mortars after curing for 28 days increased gradually as sand content increased.

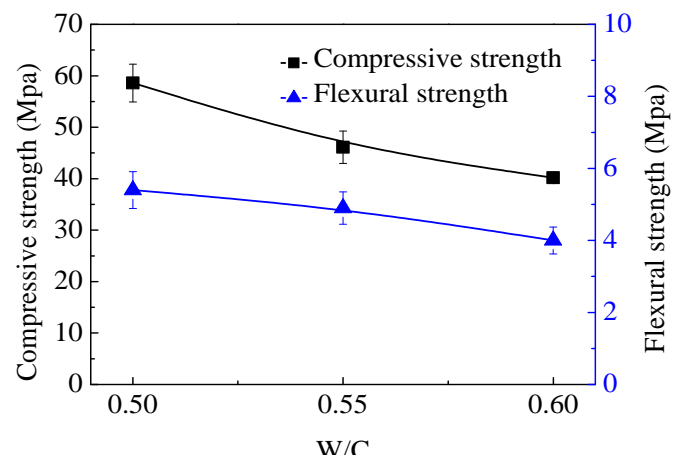

(a) different water-to-cement ratio

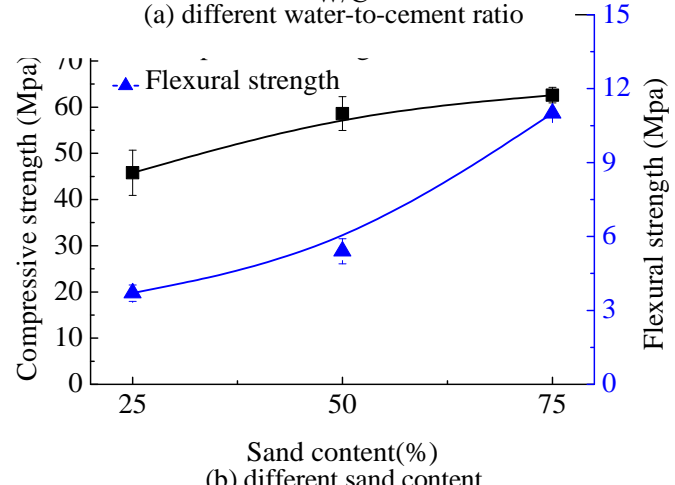

(b) different sand content

Figure 1. Strength of MSH mortar after curing for $28 \mathrm{~d}$.

\section{B. Chloride Ion Penetration Resistance Analysis}

After the chloride ion penetration resistance test, the specimens were taken out and broken in half. The depth after color development with $\mathrm{AgNO}_{3}$ is shown in Fig. 2. According to Chinese Standard GB/T50082-2009, the chloride ion diffusion coefficient was calculated using the following formula:

$$
D_{R C M}=\frac{0.0239 \times(273+T) L}{(U-2) t}\left(X_{d}-0.0238 \sqrt{\frac{(237+T) L X_{d}}{U-2}}\right)
$$

where $D_{R C M}$ is chloride ion diffusion coefficient, $U$ is the absolute value of the voltage $(V), \mathrm{T}$ is the average of the initial temperature and the end temperature of the anode solution $\left({ }^{\circ} \mathrm{C}\right), \mathrm{L}$ is the specimen height $(\mathrm{mm}), X_{d}$ is the average chloride ion penetration depth $(\mathrm{mm})$, and $\mathrm{t}$ is the testing time $(h)$. The MSH chloride ion diffusion coefficients are shown in Tab. 3.

From the results, we can see that the chloride ion diffusion coefficient of MSH mortar increased with an 
increasing water-to-cement ratio and sand content, presumably because the pores in the mortar also increased; thus, impermeability was reduced. The chloride ion diffusion coefficient of the OPC mortars was about six times larger than that of the MSH mortars, indicating that MSH impermeability was better than that of OPC.

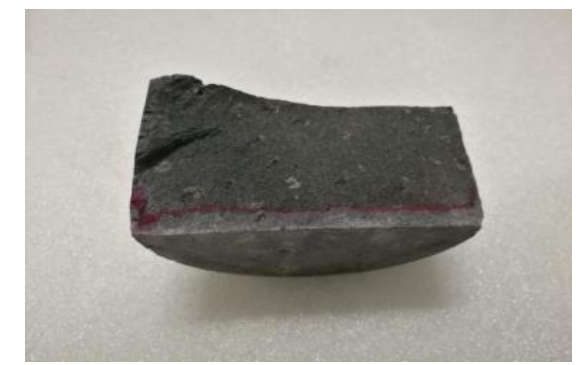

(a) MSH mortar

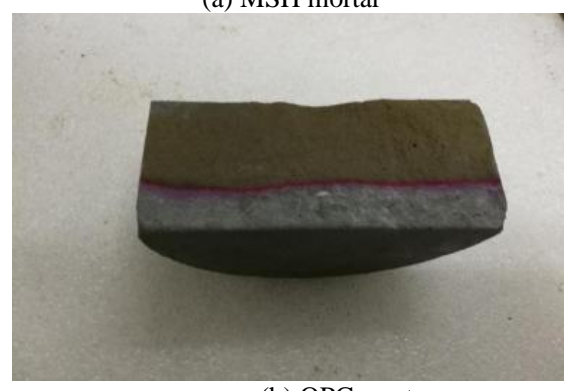

(b) OPC mortar

Figure 2. The penetration depth of chloride ion penetration resistance test.

\section{Pore Structure Analysis}

MIP has been widely used to measure medium-to-large pore structures in porous materials[13]. In this experiment, pore structure was studied via MIP (AutoPore IV 9500 Series, Micromertics Instrument Corp, USA). We obtained data for sample N2 and sample N6; results appear in Tab. 4. It was observed that the MSH cement mortar had lower porosity and total intruded volume content than OPC mortar. The porosity of MSH mortar was $9.249 \%$, about $52.7 \%$ lower than the OPC mortar. This is because the hydration products of $\mathrm{MSH}$ cement are mainly MSH gel, and the structure is dense. The OPC hydration products have more crystals, so the structure is loose.

The pore size distribution of the MSH and OPC cement mortars is shown in Fig. 3(a). MSH mortar shows a peak value of $0.036 \mathrm{ml} / \mathrm{g}$ at a pore diameter of $91082.6 \mathrm{~nm}$ and a peak of $0.031 \mathrm{ml} / \mathrm{g}$ at a pore diameter of 554.0nm. During mixing, the vibration process may be insufficient, leaving air in the specimen. When the pore diameter was less than $17.1 \mathrm{~nm}$, the amount of total intruded volume increased gradually as pore diameter decreased; this indicates that the pore size diameter of MSH mortar is mostly less than $17.1 \mathrm{~nm}$. The total intruded volume of OPC mortar was mainly between $10 \mathrm{~nm}$ and $100 \mathrm{~nm}$ and reached a maximum of $0.192 \mathrm{ml} / \mathrm{g}$ at a pore diameter of $77.1 \mathrm{~nm}$.
The cumulative pore area distribution of the mortars is shown in Fig. 3(b). It can be seen that the cumulative pore area of the different types of cement mortars was composed primarily of pores smaller than $100 \mathrm{~nm}$ increased with a decrease in pore size diameter. For MSH mortar, when the pore size diameter was less than $10 \mathrm{~nm}$, the cumulative pore area increased significantly, indicating that the MSH mortar was mainly composed of pores smaller than $10 \mathrm{~nm}$. For OPC mortar, when the pore size diameter was less than $100 \mathrm{~nm}$, the cumulative pore area increased significantly, indicating that OPC mortar was composed primarily of pores smaller than $100 \mathrm{~nm}$.
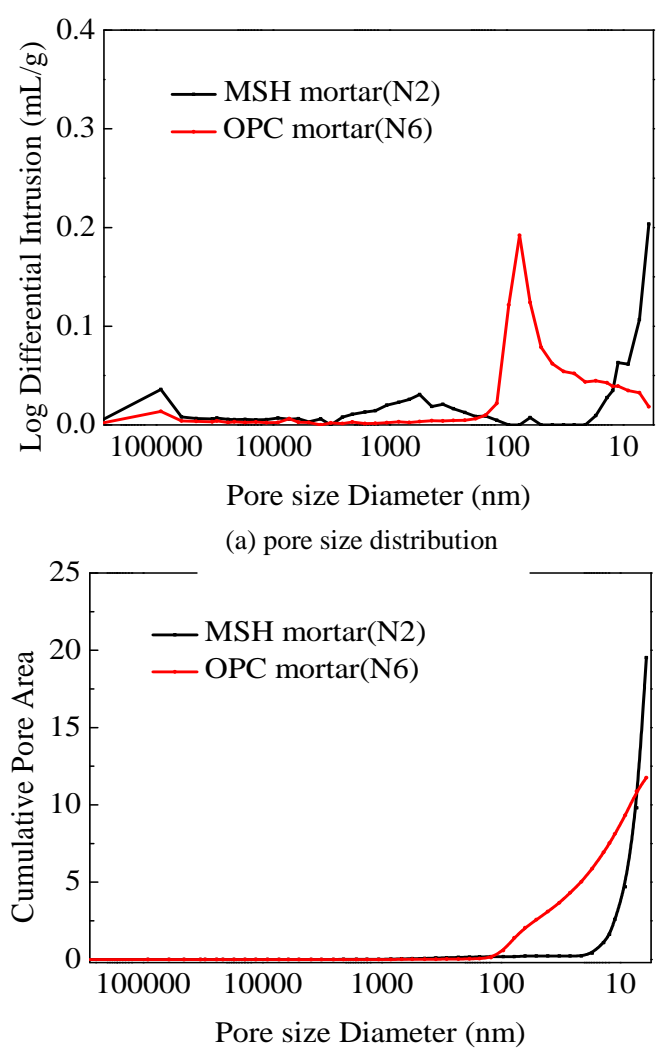

(b) cumulative pore area distribution

Figure 3. MIP analysis of cement mortar.

\section{Relationship Between Porosity and Penetrability}

The pore structure and chloride ion transport properties of concrete has been reported thoroughly in research[14]. After identifying the pore structure parameters affecting chloride ion permeability, porosity is the main factor affecting chloride ion permeation. The pores that affect the chloride ion permeability of cement-based materials are capillary pores; gel pores are not substantially affected[15]. Thus, we can conclude from the chloride ion permeation test and pore structure results that gel pore-based MSH mortars have greater impermeability than do OPC. 
TABLE III. THE PENETRATION COEFFICIENT OF MORTARS $\left(\times 10^{-12} \mathrm{~m}^{2} / \mathrm{s}\right)$

\begin{tabular}{rcccccc}
\hline & N1 & N2 & N3 & N4 & N5 & N6 \\
\hline $\begin{array}{c}\text { Penetration } \\
\text { coefficient }\end{array}$ & 1.261 & 1.455 & 1.602 & 1.523 & 1.580 & 8.802 \\
\hline
\end{tabular}

TABLE IV. MIP RESULTS

\begin{tabular}{ccccc}
\hline $\begin{array}{c}\text { Sample } \\
\text { NO. }\end{array}$ & $\begin{array}{c}\text { Total Intrusion Volume } \\
(\mathbf{m L} / \mathbf{g})\end{array}$ & $\begin{array}{c}\text { Median Pore Diameter (Area) } \\
(\mathbf{n m})\end{array}$ & $\begin{array}{c}\text { Average Pore Diameter (4V/A) } \\
(\mathbf{n m})\end{array}$ & $\begin{array}{c}\text { Porosity } \\
(\boldsymbol{\%})\end{array}$ \\
\hline N2 & 0.092 & 7.2 & 18.9 & 9.249 \\
N6 & 0.108 & 17.1 & 36.6 & 19.572 \\
\hline
\end{tabular}

\section{CONCLUSION}

(1) With an increase in the water-to-cement ratio, the mechanical properties decrease. When the sand content gradually increased, mortars' mechanical properties also increased. The compressive strength of MSH mortar was $58.6 \mathrm{Mpa}$ when the water-to-cement ratio was 0.5 and the sand content was $50 \%$. As a consequence, MSH mortar demonstrated good mechanical properties.

(2) As for MSH cement, with an increase in the water-to-cement ratio and sand content, the chloride ion diffusion coefficient gradually increased. Compared with the chloride ion diffusion coefficient of two kinds of cement mortar under the same conditions, we found the impermeability of MSH mortar to be better than that of OPC.

(3) The porosity of MSH mortar is lower than that of OPC mortar. MSH mortar was mainly composed of gel pores smaller than $10 \mathrm{~nm}$, whereas OPC mortar was mainly composed of capillary pores smaller than $100 \mathrm{~nm}$. The permeability results showed that the MSH mortar with gel pores had better impermeability than OPC mortar.

\section{ACKNOWLEDGMENT}

This research was funded by the National Natural Science Foundation of China (51778101; 61704017) and PetroChina Innovation Fundation (2016D-5007-0603).

\section{REFERENCES}

[1] T.T. Zhang, C.R. Cheeseman, L.J. Vandeperre, "Development of low $\mathrm{pH}$ cement systems forming magnesium silicate hydrate (M-S-H)," Cemnet and Concrete Research, vol. 41, 2011, pp. 439-442, doi:10.1016/j.cemconres.2011.01.016.

[2] T.T. Zhang, L.J. Vandeperre, C.R. Cheeseman, "Formation of magnesium silicate hydrate(M-S-H) cement pastes using sodium hexametaphosphate," Cemnet and Concrete Research, vol. 65, 2014, pp. 8-14, doi.org/10.1016/j.cemconres.2014.07.001.

[3] Z.H. Li, T.S. Zhang, J. Hu, et al, "Characterization of reaction products and reaction process of $\mathrm{MgO}-\mathrm{SiO}_{2}-\mathrm{H}_{2} \mathrm{O}$ system at room temperature," Construction and Building Materials, vol. 61, 2014, pp. 252-259, doi.org/10.1016/j.conbuildmat.2014.03.004.
[4] B. Lothenbach, D. Nied, E. L'Hôpital, et al, "Magnesium and calcium silicate hydrates" Cemnet and Concrete Research, vol. 77, 2015, pp. 60-68, doi.org/10.1016/j.cemconres.2015.06.007.

[5] D. Nied, K E. Rasmussen, Emilie L'Hopital, etc, "Properties of magnesium silicate hydrates (M-S-H)," Cemnet and Concrete Research, vol. 79, 2016, pp. 323-332, doi.org/10.1016/j.cemconres.2015.10.003.

[6] T.T. Zhang, L.J. Vandeperre, C.R. Cheeseman, "Magnesium-silicate-hydrate cements for encapsulating problematic aluminium containing wastes," Journal of Sustainable Cement Based Materials, vol. 1, 2012, pp. 34-45, doi.org/10.1080/21650373. 2012.727322.

[7] J. Szczerba, R. Prorok, E. Śnieżek, et al, "Influence of time and temperature on ageing and phases synthesis in the $\mathrm{MgO}-\mathrm{SiO}_{2}-\mathrm{H}_{2} \mathrm{O}$ system," Thermochimica Acta, vol. 567, 2013, pp. 57-64, doi.org/10.1016/j.tca.2013.01.018.

[8] P. Zhang, Q. Liu, W.C. Geng, et al, "Migration of water and chloride ions into mortar," Journal of the Chinese Ceramic Society, vol. 45, 2017, $235-241$, doi:10.14062/j.issn.0454-5648.2017.02.09.

[9] J.O. Rivera-Corral, G. Fajardo, G. Arliguie, et al, "Corrosion behavior of steel reinforcement bars embedded in concrete exposed to chlorides: Effect of surface finish," Construction and Building Materials, vol. 147, 2017, pp.815-826, doi.org/10.1016/j.conbuildmat.2017.04.186.

[10] W. Zhu, R. Françoiset, Q. Fang, et al. Influence of long-term chloride diffusion in concrete and the resulting corrosion of reinforcement on the serviceability of RC beams. Cement and Concrete Composites. (71)2016:144-152.

[11] J. Liu, X.C. Chen, F. Xing, et al, "The chloride ion permeability of concrete surface water seepage coefficient and the influence of the microstructure," Journal of Functional materials, vol. 45, 2014, pp. 11096-11100, doi:10.3969/j.issn.1001-9731.2014.11.020.

[12] T.T. Zhang, X.M. Liang, C.M. Li, et al, "Control of drying shrinkage in magnesium silicate hydrate(m-s-h) gel mortars," Cement and Concrete Research, vol. 88, 2016, pp. 36-42, doi.org/10.1016/j.cemconres.2016.05.011.

[13] N. Alderete, Y. Villagrán, A. Migon, et al, "Pore structure description of mortars containing ground granulated blast-furnace slag by mercury intrusion porosimetry and dynamic vapour sorption," Construction and Building Materials, vol. 145, 2017, pp. 157-165, doi.org/10.1016/j.conbuildmat.2017.03.245.

[14] C.S. Poon, S.C. Kou, L. Lam, "Compressive strength, chloride diffusivity and pore structure of high performance metakaolin and silica fume concrete," Construction and Building Materials, vol. 20, 2006, pp. 858-865, doi.org/10.1016/j.conbuildmat.2005.07.001.

[15] T. C. Powers, "Structure and physical properties of hardened Portland cement paste," Journal of the American Ceramic Society, vol. 41, 1958, pp. 1-6, doi. 10.1111/j.1151-2916.1958.tb13494.x. 